\title{
ASPECTOS GENÉTICOS E MORFOLÓGICOS DAS CAVIDADES NATURAIS DA SERRA DA PIEDADE, QUADRILÁTERO FERRÍFERO/MG
}

\section{GENETIC AND MORPHOLOGYCAL ASPECTS OF NATURAL CAVITIES IN SERRA DA PIEDADE'S RIGDE, QUADRILÁTERO FERRÍFERO/MG}

Manuela Corrêa Pereira

Instituto de Geociências/UFMG - Avenida Antônio Carlos, 6.627 Pampulha - CEP: 31270-901 e-mail:manuelacp1@gmail.com.

Joël Georges Marie André Rodet CNRS/UMR 6143 - Laboratoire de Géologie de l'Université de Rouen, 76821 Mont Saint Aignan, France. e-mail: joel.rodet@univ-rouen.fr/joel.rodet@gmail.fr

André Augusto Rodrigues Salgado Instituto de Geociências/UFMG - Avenida Antônio Carlos, 6.627 Pampulha - CEP: 31270-901 e-mail:geosalgado@yahoo.com.br

\section{Informações sobre o Artigo}

Data de Recebimento:

01/06/2012

Data de Aprovação:

23/05/2013

\section{Palavras-chave:}

Cavernas, Serra da Piedade, processos cársticos, itabirito, canga

\section{Keywords:}

Caves, Serra da Piedade, karst processes, itabirite, iron crust.

\begin{abstract}
Resumo
Os estudos acadêmicos sobre cavidades naturais em formações ferríferas bandadas e canga, no Quadrilátero Ferrífero - Minas Gerais, são escassos diante do potencial espeleológico desta província mineral. Dentro deste contexto, as cavidades naturais da Serra da Piedade foram objeto do estudo, que tem como principal objetivo levantá-las e classificá-las, de acordo com seus aspectos morfológicos e genéticos, assim como analisar sua distribuição ao longo do relevo. Para isso, os seguintes procedimentos metodológicos foram realizados: (i) revisão bibliográfica, (ii) caracterização da área de estudo; (iii) compartimentação do relevo; (iv) prospecção e análise em campo dos aspectos morfológicos e genéticos; (v) mensuração da projeção horizontal das cavidades, através de medidas realizadas em campo e mapeamento topográfico; e (vi) análise e discussões dos resultados. Os resultados obtidos evidenciaram que existem três tipos de cavidades na Serra da Piedade: cavernas em tálus; cavernas com feições cársticas e cavernas onde não foi possível constatar evidências morfocársticas. De maneira geral, as cavidades formadas por acumulação de matacões encontram-se nos patamares altimétricos mais elevados, entretanto, estão situadas numa declividade relativamente suave. Já grande parte das
\end{abstract}


cavernas sem evidências morfocársticas e das cavernas com feições cársticas estão localizadas na borda do platô de canga. Entretanto, a caverna de maior projeção horizontal está inserida no interior da unidade escarpa norte. Quanto ao desenvolvimento das cavernas topografadas, constatou-se que aquelas com feições cársticas são maiores do que as cavernas sem evidências morfocársticas. Pode-se concluir que ocorreram processos de carstificação em cavernas e feições superficiais desenvolvidas no itabirito e na canga, embora as mesmas não sejam tão desenvolvidas como as feições presentes em rochas carbonáticas e siliciclásticas.

\begin{abstract}
The present study aims to raise and sort Serra da Piedade's caves, in accordance with their morphological and genetic aspects, as well as to analyze its distribution along the relief. To this, the following methodological procedures were carried out: (i) literature review, (ii) study area featuring, (iii) relief partitioning, (iv) prospection and analysis of morphological and genetic features in the field, (v) cavity horizontal projection measurement through field measurements and topographic mapping, and (vi) results analysis and discussion. Results showed that there are three cavity sorts in Serra da Piedade: talus caves, karst featured caves and caves where it was not possible to verify morphokarstic evidence. In general, the cavities formed by boulders accumulation are at higher altimeters levels, however, they are located in a relative smooth slope. Most of the caves without morphokarstic evidence and karst featured caves are situated on the iron crust edge. Nevertheless, the largest horizontal projection cave is inserted into the north slope. Concerning the development of topographed caves, it was found that those with karst features are larger than the caves without morphokarstic evidence. It can be concluded that karstification processes occurred in caves and superficial features were developed on itabirite and iron crust, although these are not as developed as the features found in carbonate and siliciclastic rocks.
\end{abstract}

\section{Introdução}

Cavernas em formações ferríferas e canga têm sido referenciadas em diversos países como, por exemplo, Nigéria, Venezuela, França (Guiana Francesa), Serra Leoa e Austrália (BOWDEN, 1980, BOYÉ \& PASCUAL, 1977, MOSS 1965, TWIDALE, 1987, MCFARLANE \& TWIDALE, 1987). Dentre esses estudos, destacam-se os que buscaram descrever e caracterizar os processos inerentes à gênese destas cavidades. Boyé \& Pascual (1977) relatam que as cavidades e depressões presentes nas lateritas de bauxita da montanha de Roura, Guiana Francesa, são fruto da combinação de três processos: alteração, dissolução e piping. Bowden (1980) classifica as cavernas localizadas na região da montanha Kasewe Hills (Serra Leoa) como pseudocársticas. Este autor relata que a gênese destas feições está relacionada a processos como intemperismo, piping e colapso. Por sua vez, McFarlane e Twidale (1987) já consideram cársticas, feições desenvolvidas em rochas não carbonáticas. Sendo assim, quanto à gênese de feições cársticas desenvolvidas em terrenos lateríticos, os autores supõem que a ação de microorganismos pode ser essencial para que haja a dissolução e formação destas feições neste litotipo.

Apesar de este tema ter sido abordado na literatura científica internacional, no Brasil foram poucos os estudos que investigaram as cavidades desenvolvidas em rochas ferríferas como a canga e o itabirito. Dentre estes poucos estudos, destaca-se o de Simmons (1963) que afirmou existirem duas tipologias de cavidades em formações ferríferas e canga no Quadrilátero Ferrífero/MG: as formadas por erosão e as formadas por dissolução, sendo que algumas cavidades resultam da ação combinada dos dois processos. Para este autor, as cavernas de erosão ocorrem imediatamente abaixo de mantos de canga. Já as cavernas de dissolução ocorrem sob a canga no contato com o itabirito da Formação Cauê. As cavernas desta tipologia apresentam salões e condutos que se assemelham aos encontrados em rochas carbonáticas.

Piló \& Auler (2005) observaram que as cavernas em formações ferríferas da região de Capão Xavier no Quadrilátero Ferrífero/MG também se assemelham as cavernas descritas por Simmons (1963). Logo, na região do Capão Xavier haveria "cavernas de erosão" e "cavernas de dissolução". Entretanto, estes autores não utilizaram esta terminologia, pois acreditam que mesmo nas cavernas denominadas "erosivas" pode haver a ocorrência da ação dissolutiva.

Por fim, Stávale (2007), diferenciou as cavernas com substrato ferruginoso do Parque Estadual Serra do Rola Moça no Quadrilátero Ferrífero/MG em duas tipologias: cavidades formadas por processos endógenos e exógenos. As endógenas possuiriam dimensões maiores e teriam processos de dissolução associados a sua gênese. Já as exógenas ocorreriam graças ao processo de retração lateral da vertente, onde o itabirito subjacente à canga é erodido e esta carapaça sustenta o teto da cavidade.

Apesar da existência destes estudos, a maior parte do Quadrilátero Ferrífero/MG nunca teve suas cavidades em formações ferríferas e canga, academicamente, estudadas. A própria dimensão deste fenômeno é ainda desconhecida. Tal desconhecimento torna-se extremamente grave quando se considera que o aumento da procura por minério de ferro no mercado internacional tem causado uma expansão da atividade mineraria e, consequentemente, a supressão de inúmeras cavidades. 
Neste contexto, situa-se o presente trabalho que objetiva estudar as cavidades naturais e as feições superficiais nas formações ferríferas bandadas e nas cangas da Serra da Piedade - extremo norte do Quadrilátero Ferrífero/MG. Neste estudo, buscou-se levantar e classificar estas feições, de acordo com seus aspectos morfológicos e genéticos, assim como relacionar a distribuição das cavernas com o relevo da área de estudo. A escolha da área justifica-se pelo fato de que a Serra da Piedade, apesar de apresentar grande ocorrência de formações ferríferas bandadas e de canga, nunca teve suas cavidades levantadas ou exploradas. Paralelamente, destacase o fato de que esta serra é uma área de grande importância ambiental e histórica, sendo inclusive tombada nas escalas municipal, estadual e federal.

\section{A Serra da Piedade}

A Serra da Piedade situa-se na porção norte do Quadrilátero Ferrífero/MG (Figura 1). Ela está localizada entre os municípios de Sabará/MG e Caeté/MG e possui um grande significado para história social, cultural e religiosa de Minas Gerais. A história de sua ocupação está relacionada ao bandeirismo do século XVII, sendo que, desde então a Serra da Piedade foi descrita por diversos viajantes. Dentre eles, destacam-se Wilhelm Ludwig von Eschwege, Auguste de Saint-Hilaire, Johannes Eugenius Bülow Warming. (RUCHKYS, 2007).
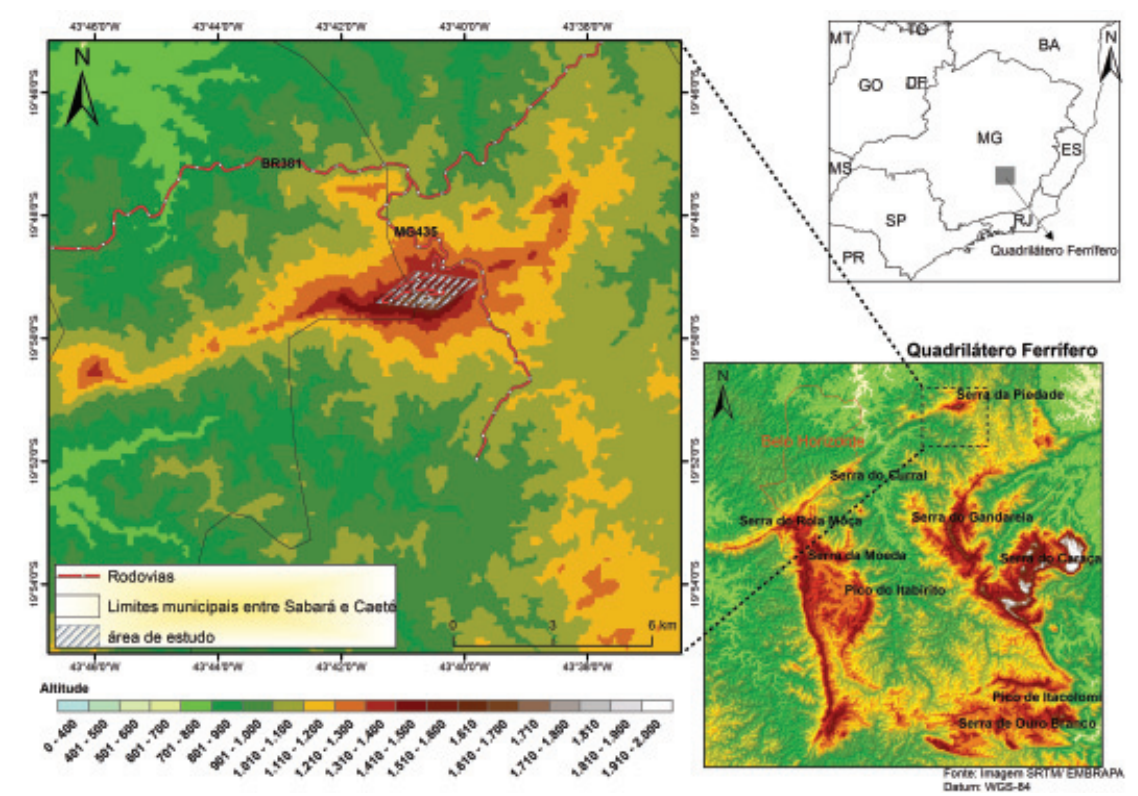

Figura 1 - Localização da Serra da Piedade e do Quadrilátero Ferrifero.

O clima da Serra da Piedade é classificado como tropical semi-úmido e tropical de altitude, nas cotas altimétricas mais elevadas. A média da temperatura do mês mais frio é de $18^{\circ} \mathrm{C}$ e do mês mais quente $22^{\circ} \mathrm{C}$, entretanto, a média da temperatura anual do topo da serra é de $16^{\circ} \mathrm{C}$ (VIANELLO \& MAIA, 1986). No que tange às características pluviométricas, destaca-se a ocorrência de chuvas orogênicas, provocadas pela barreira montanhosa da Serra. Estas chuvas ocorrem, principalmente, na vertente sul.

Em termos de vegetação, assim como diversas outras serras do Quadrilátero Ferrífero, o porte arbóreo está associado ao substrato litológico (LAMOUNIER et al. 2010). No sopé tem-se a mata fechada de encosta, remanescente da floresta tropical que recobria a extensa área de Minas Gerais. Já no topo constata-se uma vegetação rasteira de menor porte, que pode ser classificada como campo de altitude ou campo rupestre.

\section{Geologia e Geomorfologia}

Na região da Serra da Piedade afloram (ALKMIN \& MARSHAK, 1998): (i) os granito-gnaisse de idade arqueana do embasamento cristalino; (ii) os xistos e filitos também de idade arqueana do Grupo Nova Lima - Supergrupo Rio das Velhas - e; (iii) as rochas proterozóicas do Supergrupo Minas (Figura 2). Na Serra da Piedade, o Supergrupo Minas é representado pelos seguintes grupos: (i) Caraça, com os quartizitos ferruginosos da Formação Moeda; (ii) Itabira, com os itabiritos da Formação Cauê; e (iii) Piracicaba, com os filitos e xistos da Formação Sabará e com os filitos e quartizitos ferruginosos da Formação Cercadinho. De um modo geral, recobrindo os itabiritos da Formação Cauê (Grupo Itabira), ocorrem formações de canga de idade terciária (Figura 2). 


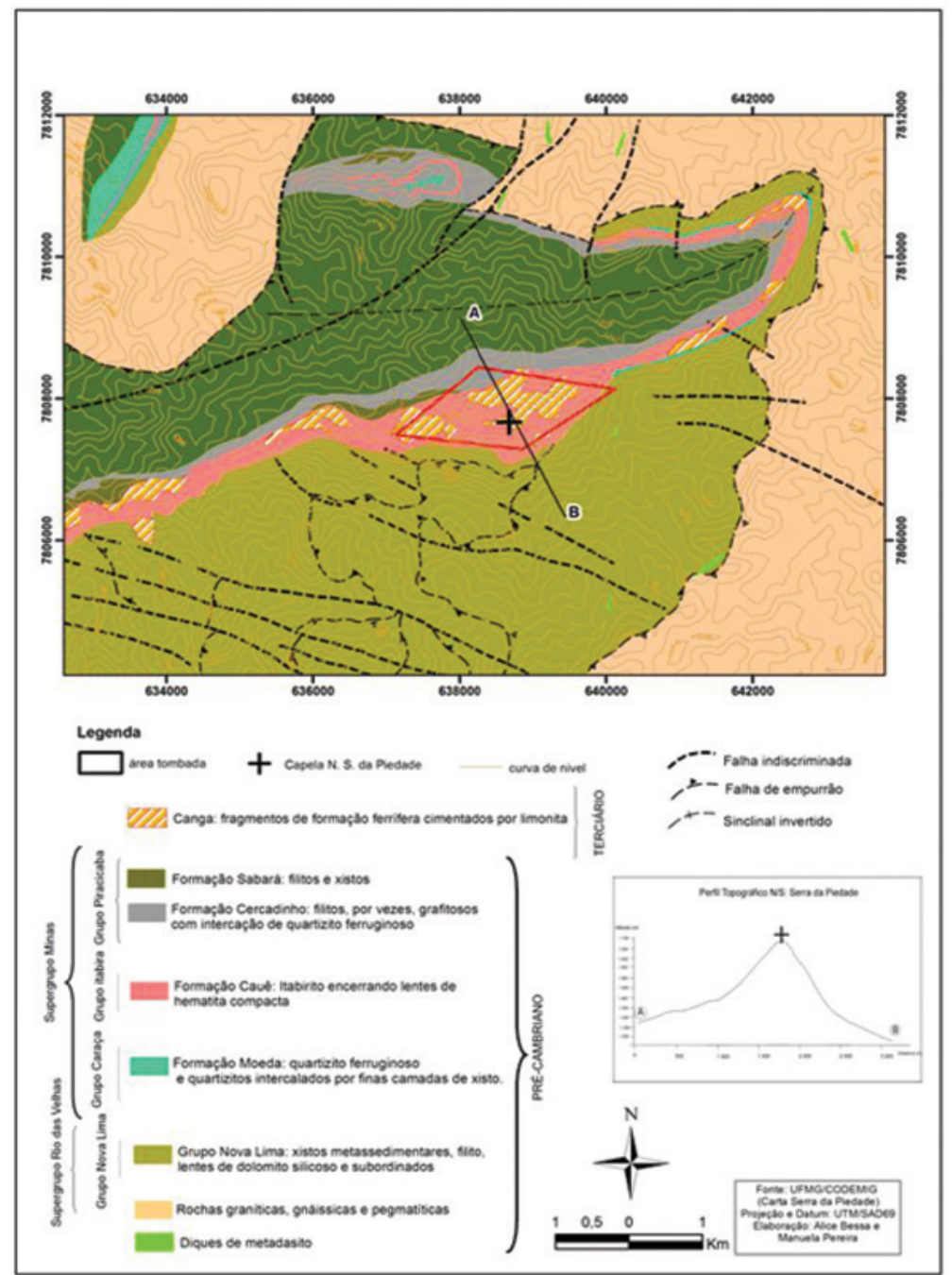

Figura 2 - Mapa Litológico da Serra da Piedade. Através das curvas de nivel e do perfil A-B é possível constatar que a vertente sul é mais abrupta que a vertente norte.

O relevo da área de estudo, a exemplo de todo o Quadrilátero Ferrífero/MG, guarda estreita relação com o substrato e evoluiu por erosão diferencial. Neste contexto, as áreas que tem por substrato as cangas, quartzitos e itabiritos sustentam as porções mais elevadas do relevo e, àquelas que se situam sobre xistos, filitos e granito-gnaisse apresentam-se topograficamente rebaixadas (HARDER \& CHAMBERLIN, 1915; TRICART, 1961; BARBOSA \& RODRIGUES, 1967; BARBOSA, 1980; SALGADO, 2006; SALGADO et al., 2004, 2007A, 2007B, 2008).

\section{Procedimentos metodológicos}

A execução desta pesquisa envolveu etapas de gabinete e de campo.
Na primeira etapa de gabinete foi feito um levantamento bibliográfico sobre cavernas em formações ferríferas bandadas e canga, assim como acerca das características ambientais da área em estudo. Posteriormente, foi compilado o mapa de compartimentação do relevo, elaborado a partir de mapas hipsométrico e de declividade (gerados a partir da imagem SRTM/EMBRAPA) e do mapa geológico (quadrícula da Serra da Piedade, CODEMIG/GEOMINAS). Além disso, utilizouse a imagem de satélite (SPOT, 2002) e reconhecimento em campo para auxiliar na interpretação do relevo. Os mapas foram compilados e elaborados utilizando o software ARCGIS, versão 9.2. Para a confecção do mapa de compartimentação do relevo, utilizou-se de forma adaptada e simplificada as instruções do Manual Técnico de Geomorfologia (NUNES \& IBGE, 1995). 
Posteriormente, na etapa de campo, foram levantadas as cavidades localizadas na escarpa norte e sul da Serra da Piedade, totalizando uma área de 192ha. Optou-se por concentrar as campanhas de prospecção na escarpa norte em razão de que, dentre as porções da serra tombadas, esta era a que apresentava a maior área com capeamento de canga. Após a prospecção, foram analisados aspectos como feições cársticas presentes no interior das cavernas e feições cársticas superficiais. Por fim, mensurou-se a projeção horizontal aproximada das cavernas levantadas, através de medidas realizadas em campo e de mapeamento topográfico.

Os dados da projeção horizontal das cavidades foram subdivididos em quatro classes de tamanho: classe $1(0-15 \mathrm{~m})$, classe $2(16-30 \mathrm{~m})$, classe $3(31-45 \mathrm{~m}) \mathrm{e}$ classe 4 (acima de $45 \mathrm{~m}$ ).

Com base nos dados levantados em campo, iniciouse a segunda e última etapa de gabinete que objetivou subdividir as cavidades em três tipos e verificar as características ambientais - dimensões, inserção no relevo, substrato - de cada um destes tipos de cavidade. Os três tipos de cavidades foram: (i) cavidades formadas por queda de matacões, denominadas de cavidades em tálus; (ii) cavidades que apresentam geoformas de dissolução, denominadas de cavernas com feições cársticas e; (iii) cavidades que apesar de não terem sido formadas por que- da de blocos, não apresentam geoformas de dissolução, chamadas de cavernas sem evidências morfocársticas.

Vale ressaltar que, segundo Palmer (2007) cavidades em tálus consistem em vazios formados pela sobreposição seixos, calhau e/ou matacão. Estas cavidades estão localizadas na base de penhascos ou nos degraus de um relevo escalonado.

As cavernas com feições cársticas são referenciadas na literatura como cavernas de dissolução (Simmons, 1963; Piló \& Auler, 2005; Palmer, 2007). Neste trabalho, foram consideradas com feições cársticas devido à presença de formas que evidenciam este processo (Hardt \& Pinto, 2009).

Por fim, as cavernas sem evidências cársticas fazem parte da categoria, na qual não foi possível encontrar formas de dissolução. Entretanto, estas cavidades foram formadas in situ, ou seja, sua gênese não está associada à sobreposição de blocos.

\section{Resultados e discussões}

\section{Compartimentação do relevo da área de estudo}

Após a realização da etapa de compartimentação do relevo, foi possível constatar a existência das seguintes unidades: (i) crista, (ii) escarpa sul, (iii) escarpa norte, (iv) platôs escalonados e (v) planalto inferior (Figuras 3 e 4).
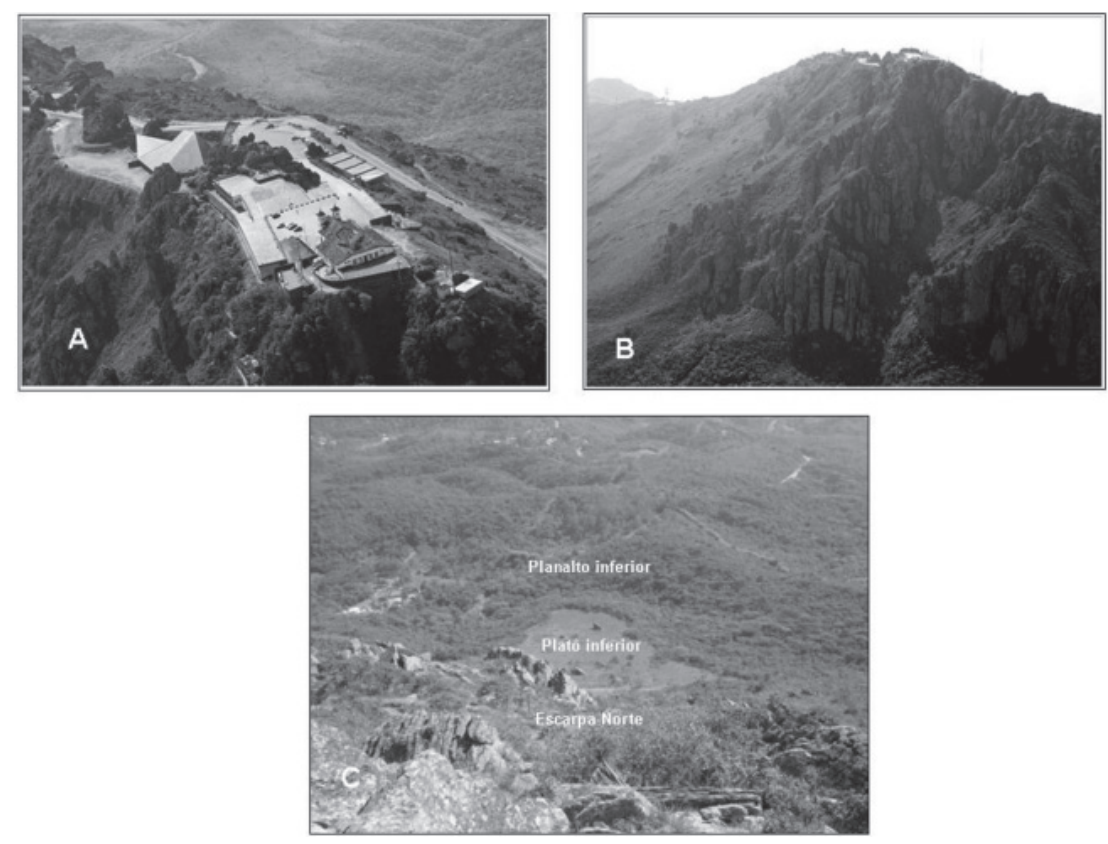

Figura 3 - (A) crista, unidade onde está situado o complexo arquitetônico do Santuário da Serra da Piedade; (B) escarpa sul, vertente mais abrupta da Serra; (C) escarpa norte em primeiro plano, platô inferior em segundo plano e planalto em terceiro plano.

Fotos: (A) e (B) Divulgação. disponível em: http://www.caetemh.com; (C) Manuela Corrêa Pereira. 


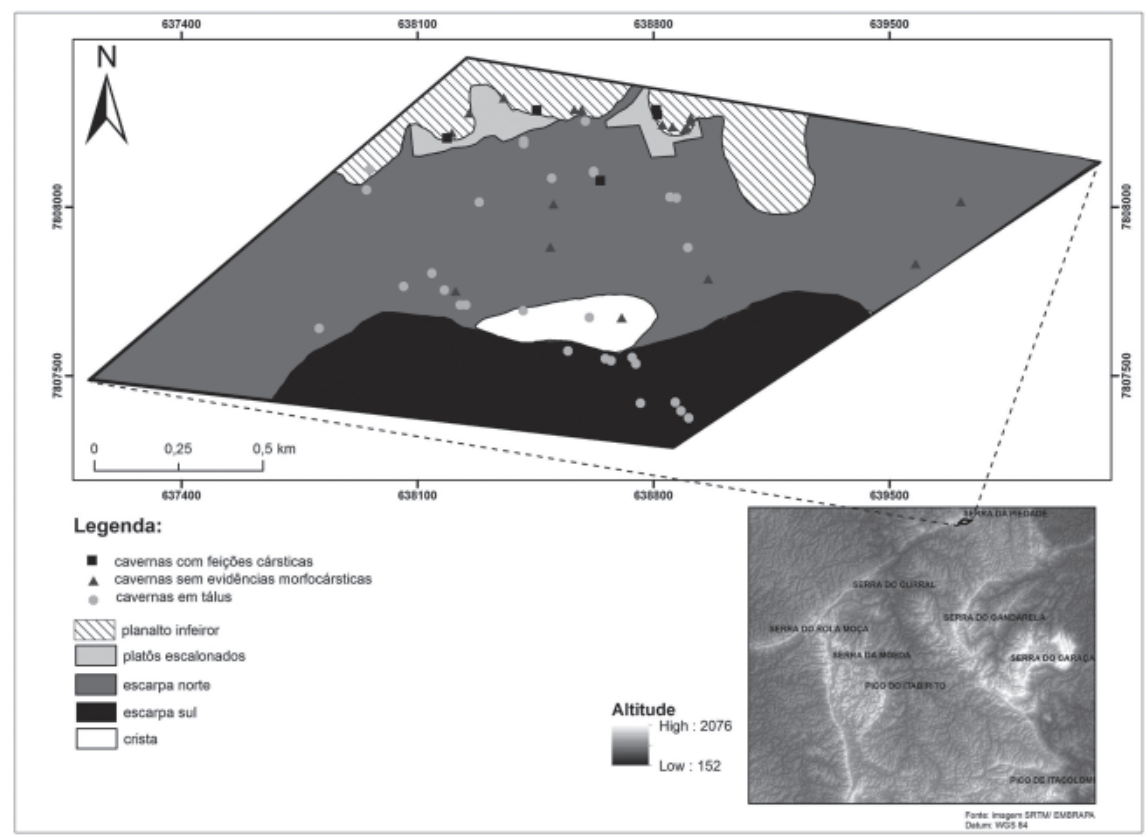

Figura 4 - Unidades do Relevo da Serra da Piedade e contextualização das cavidades levantadas no relevo da área em estudo. Fotos: Manuela Corrêa Pereira

A crista da área de estudo é representada por um topo aguçado, ou seja, estreito e alongado, localizado entre 1.700 e 1.776 metros de altitude (Figura 3-A e 4). Segundo Nunes \& IBGE (1995), estes topos são esculpidos em rochas metamórficas e sua forma é resultante da interceptação de vertentes de declividade acentuada.

A escarpa sul possui uma declividade mais acentuada quando comparada à escarpa norte, sendo nítido o contraste entre os itabiritos da Formação Cauê e os xistos do Grupo Nova Lima (Figura 2). Esta vertente está localizada entre 1.500 e $1.700 \mathrm{~m}$ de altitude. Ela é caracterizada pela presença de afloramentos de itabiritos (Figuras 3-B e 4).

A escarpa norte, situada entre 1.420 e $1.700 \mathrm{~m}$ de altitude, é relativamente mais suave quando comparada à escarpa sul (Figura 3-C e 4). Tal fato pode estar associado à presença de capas de canga, conforme constatado no mapa litológico (CODEMIG/GEOMINAS) (Figura 2).

Os platôs escalonados estão localizados na escarpa norte. O platô superior está situado entre 1.440 e $1.480 \mathrm{~m}$. Já o platô inferior situa-se entre as cotas altimétricas de 1.380 e $1.420 \mathrm{~m}$ (Figuras 3-C e 4).

Por fim, a área de estudo engloba parte do planalto inferior que é caracterizado por um substrato filítico, pertencente à Formação Cercadinho. Este planalto está em contato com as bordas dos platôs e, na área de estudo, situa-se entre 1.360 e $1.560 \mathrm{~m}$ de altitude (Figuras 3-C e 4).

\section{Classificação dos tipos de cavidades da Serra da Piedade}

$\mathrm{Na}$ área em estudo foram levantadas 52 cavidades naturais (Figura 4). Dentre estas, vinte e nove são cavidades em tálus, cinco são cavernas que apresentam feições cársticas e dezoito foram classificadas como cavernas sem evidências morfocársticas (Tabela 1).

Através da análise da projeção horizontal das cavidades levantadas (Tabelas 1, 2 e Figura 5), constatou-se que as cavidades em tálus possuem um desenvolvimento inibido quando comparada às demais categorias. Portanto, todas as cavidades deste tipo estão nas classes de tamanho 1 ou 2. As cavernas sem evidências cársticas também possuem um desenvolvimento inibido e estão representadas pelas classes 2, 3 e principalmente, pela classe 1 . Por fim, as cavernas com feições cársticas se diferem do comportamento dos demais tipos de cavidades. Esta categoria é representada, principalmente pela classe 4 que, na área de estudo, contém cavernas com projeção horizontal de até $365 \mathrm{~m}$. 
Tabela 1- Classificação das cavidades levantadas.

\begin{tabular}{|c|c|c|c|}
\hline Caverna & Coordenada UTM $(x)$ & Coordenada UTu (y) & classificação \\
\hline GP1 (Gruta da Piedade) & 638643 & 7808078 & caverns com feiçoes cársticastálus \\
\hline GP2 (Gruta do Cascahinho) & 638809 & 7808288 & caverna com feiçoles cársticas \\
\hline GP3 (Gruta da Macumba) & 638812 & 7808274 & caverna com feiç̧⿸es cárstica \\
\hline GP4 (Gruta da Clarabóia) & 638827 & 7808244 & caverns sem evidéncias morfocársticas \\
\hline GP5 (Gruta da Latnha) & 638857 & 7808238 & caverna sem evidéncias morfocársticas \\
\hline GP6 (Gruta do conduto I) & 638820 & 7808179 & caverna sem evidéncias morfocársticas \\
\hline GP7 (Gruta do conduto li) & 638820 & 7808180 & caverna sem evidencias morfocársticas \\
\hline GPB (Gruta Pequena) & 638910 & 7808255 & caverna sem evidèncias morfocársticas \\
\hline GP9 (Gruta do Morcego) & 638911 & 7808265 & caverna sem evidéncias morfocársticas \\
\hline GP10 (Gruta da Placa azu) & 638706 & 7807672 & caverna sem evidéncias morfocársticas \\
\hline GP11 (Guta do Ato da Piedade) & 638623 & 7808102 & eaverna em tálus \\
\hline GP12 & 638623 & 7808106 & 3 caverna em tálus \\
\hline GP13 (Gruta dos Romeiros) & 638599 & 7808255 & caverna em tálus \\
\hline GP14 & 638416 & 7808197 & caverna em tálus \\
\hline GP15 & 638416 & 7808188 & caverns em tálus \\
\hline GP16 (Gruta do coichăo) & 638504 & 7808009 & caverna sem evidéncias morfocársticas \\
\hline GP17 & 638499 & 7808086 & caverna em tálus \\
\hline GP18 (Gruta do Eremta) & 638244 & 7807710 & caverna em tálus \\
\hline GP19 & 638227 & 7807710 & caverna em tálus \\
\hline GP20 & 638181 & 7807754 & caverna em talus \\
\hline GP21 & 638060 & 7807765 & caverna em tálus \\
\hline GP22 (Gruta do Banheiro) & 638214 & 7807751 & caverns sem evidéncias morfocársticas \\
\hline GP23 & 638284 & 7808015 & Caverns em talus \\
\hline GP24 & 637959 & 7808111 & caverna em tálus \\
\hline GP25 & 637950 & 7808051 & caverna em tálus \\
\hline GP26 (Gruta dos Monges) & 639578 & 7807832 & caverna sem evidéncias morfocérsticas \\
\hline GP27 (Gruta do desisto) & 639712 & 7808016 & caverna sem evidéncias morfocírsticas \\
\hline GP28 (Gruta pequena I) & 638566 & 7808289 & caverna sem evidéncias morfocársticas \\
\hline GP29 (Gruta do chuverinho) & 638454 & 7808287 & caverna com feicöes cársticas \\
\hline GP30 (Gruta do capim) & 638357 & 7808324 & caverna sem evidências morfocársticas \\
\hline GP31 (Gruta do meio) & 638254 & 7808279 & caverna sem evidências morfocársticas \\
\hline GP32 (Gruta do bloco abatido) & 638203 & 7808220 & caverna sem evidências morfocársticas \\
\hline GP33 (Gruta do triângulo) & 638188 & 7808204 & caverna com feicōes cársticas \\
\hline GP34 & 638349 & 7808030 & caverna em talus \\
\hline GP35 (Gruta da árvore seca) & 638069 & 7808027 & caverna em tálus \\
\hline GP36 & 638903 & 7807880 & caverna em tálus \\
\hline GP37 & 638611 & 7807673 & caverna em tálus \\
\hline GP38 & 638749 & 7807536 & caverna em tálus \\
\hline GP39 & 638738 & 7807554 & caverna em talus \\
\hline GP40 & 638675 & 7807545 & caverna em tálus \\
\hline GP41 & 638658 & 7807551 & caverna em tálus \\
\hline GP42 & 638762 & 7807419 & caverna em tálus \\
\hline GP43 & 638547 & 7807574 & caverna em tálus \\
\hline GP44 & 638882 & 7807396 & caverna em tálus \\
\hline GP45 & 638905 & 7807375 & caverna em tálus \\
\hline GP46 & 638365 & 7807421 & caverna em tálus \\
\hline GP47 & 638414 & 7807693 & caverna em tálus \\
\hline GP48 & 638143 & 7807804 & caverng em tálus \\
\hline GP49 & 637809 & 7807641 & caverna em tálus \\
\hline GP50 (Gruta da estrada l) & 638963 & 7807787 & caverna sem evidências mortocársticas \\
\hline GP51 (Gruta da estrada II) & 638495 & 7807882 & caverna sem evidências morfocársticas \\
\hline GP52 (Gruta do desisto) & 638588 & 7808289 & caverna sem evidências mortocársticas \\
\hline
\end{tabular}

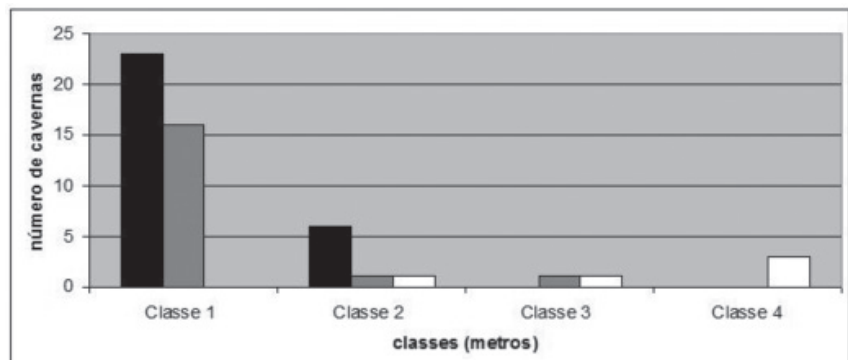

- Cavemas em tálus a Cavemas sem evidências cársticas 口 Cavemas com evidéncias cársticas

Figura 5 - Frequência das classes de projeção horizontal das três categorias de cavernas da Serra da Piedade.

\section{Inserção das cavidades na paisagem}

Foi constatado que as cavidades em tálus da vertente norte estão localizadas na escarpa norte, nos patamares altimé- tricos mais elevados (1600 a $1700 \mathrm{~m}$ ). Esperava-se que estas cavidades estivessem localizadas na unidade platôs. Entretanto, a escarpa norte apresenta porções de baixa declividade em relação ao entorno (10 a 30\%). Já a gênese das cavidades em tálus da vertente sul foi favorecida pela associação dos afloramentos de itabirito com os blocos desta mesma litologia.

\section{Tabela 2 - Projeção horizontal, inserção no relevo e litologia das cavernas da Serra da Piedade}

\begin{tabular}{|c|c|c|c|}
\hline Caverna & Projeção horizontal aprox. (m) & Inserçãa no relevo & Ltologia \\
\hline GP1 & 365 & escarpa norte & canga detrtica/tabirta/matacóes de tabirto \\
\hline GP2 & 30 & platô superior & canga detratica/thabirto \\
\hline GP3 & 27 & platô superior & canga detritica/ttabirto \\
\hline GP4 & 11 & platô superior & canga detritica/tabirto \\
\hline GP5 & 21 & platố superior & canga detritica/tabirto \\
\hline GP6 & 5 & platô superior & canga detritica/tiabirto \\
\hline GP7 & 7 & platô superior & canga detritica/tabirto \\
\hline GP8 & 2 & platô superior & canga detritica/tabirto \\
\hline GP9 & 8 & platô superior & canga detritica/tabirto \\
\hline GP10 & 9 & crista & canga detritica/tabirto \\
\hline GP11 & 14 & escarpa norte & matacöes de itabirto \\
\hline GP12 & 6 & escarpa norte & matacões de itabirito \\
\hline GP13 & 19 & escarpa norte & matacões de tabirito \\
\hline GP14 & 14 & escarpa norte & matacōes de itabirito \\
\hline GP15 & 6 & escarpa norte & matacões de itabirito \\
\hline GP16 & 6 & escarpa norte & canga detritica/tabirto \\
\hline GP17 & 6 & escarpa norte & matacões de itabirito \\
\hline GP18 & 7 & escarpa norte & matacões de itabirito \\
\hline GP19 & 6 & escarpa norte & matacōes de itabirito \\
\hline GP20 & 5 & escarpa norte & matacőes de itabirito \\
\hline GP21 & 5 & escarpa norte & matacőes de itabirto \\
\hline GP22 & 6 & escarpa norte & canga detritica \\
\hline GP23 & 12 & escarpa norte & matacões de itabirito \\
\hline GP24 & 9 & platô inferior & matacões de itabirito \\
\hline GP25 & 8 & escarpa norte & matacōes de itabirito \\
\hline GP26 & 35 & escarpa norte & canga detritica/tabirto \\
\hline GP27 & 4 & escarpa norte & canga detritica \\
\hline GP28 & 4 & platô inferior & canga detritica \\
\hline GP29 & 70 & platô inferior & canga detritica/tiabirto \\
\hline GP30 & 10 & platô inferior & canga detritica \\
\hline GP31 & 6 & platô inferior & canga detritica \\
\hline GP32 & 10 & platô inferior & canga detritica/tabirto \\
\hline GP33 & 102 & platô inferior & canga detritica/tabirto \\
\hline GP34 & 5 & platô inferior & matacões de itabirito \\
\hline GP35 & 8 & escarpa norte & matacões de itabirito \\
\hline GP36 & 5 & escarpa norte & matacōes de itabirtto \\
\hline GP37 & 5 & crista & matacões de itabirito \\
\hline GP38 & 6 & escarpa sul & matacóes de itabirito \\
\hline GP39 & 6 & escarpa sul & matacôes de itabirito \\
\hline GP40 & 15 & escarpa sul & matacões de itabirito \\
\hline GP41 & 6 & escarpa sul & matacões de tabirito \\
\hline GP42 & 18 & escarpa sul & matacōes de itabirito \\
\hline GP43 & 16 & escarpa sul & matacões de itabirito \\
\hline GP44 & 5 & escarpa sul & matacốes de itabirto \\
\hline GP45 & 26 & escarpa sul & matacões de itabirito \\
\hline GP46 & 15 & escarpa sul & matacóes de itabirito \\
\hline GP47 & 12 & crista & matacōes de itabirito \\
\hline GP48 & 11 & escarpa norte & matacões de itabirito \\
\hline GP49 & 5 & escarpa norte & matacőes de tabirito \\
\hline GP50 & 6 & escarpa norte & canga detritica/tabirto \\
\hline GP51 & 4 & escarpa norte & canga detrntica \\
\hline GP52 & 2 & platô inferior & canga detritica \\
\hline
\end{tabular}

As cavernas com feições cársticas estão localizadas nas bordas dos platôs. Entretanto, a caverna de maior projeção horizontal encontra-se na unidade escarpa norte (Figuras 4 e 6). Já as cavernas sem evidências cársticas, encontram-se nas unidades platôs, escarpa norte e crista. Foi constatado 
que todas estas cavidades são desenvolvidas, imediatamente, abaixo do manto de canga. As cavidades desta categoria podem estar localizadas nas bordas dos platôs ou nas bordas das capas de canga localizadas no interior da escarpa norte $\mathrm{e}$ da crista. As bordas constatadas nas unidades supracitadas não possuem continuidade lateral expressiva como as cavidades localizadas nas bordas dos platôs (Figura 7).

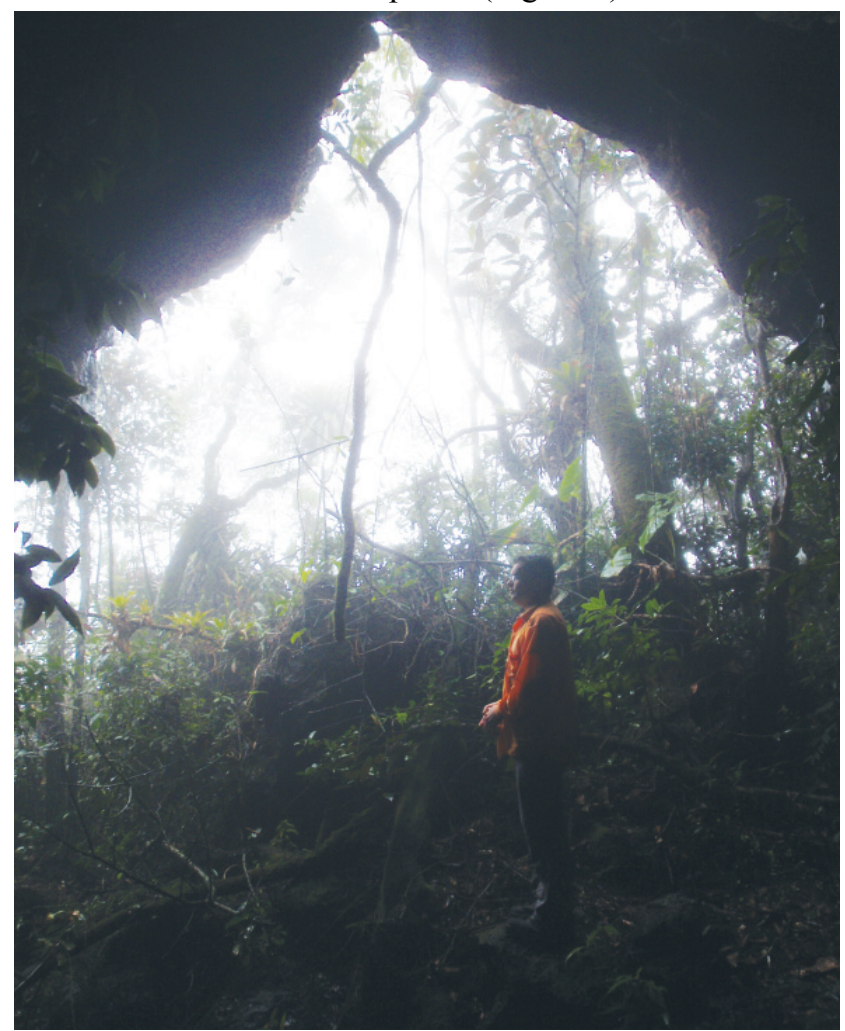

Figura 6 - Entrada da Gruta da Piedade, caverna com maior projeção horizontal, que foge do padrão de localização das demais cavernas com feições cársticas.

Foto: Leda Zogbi

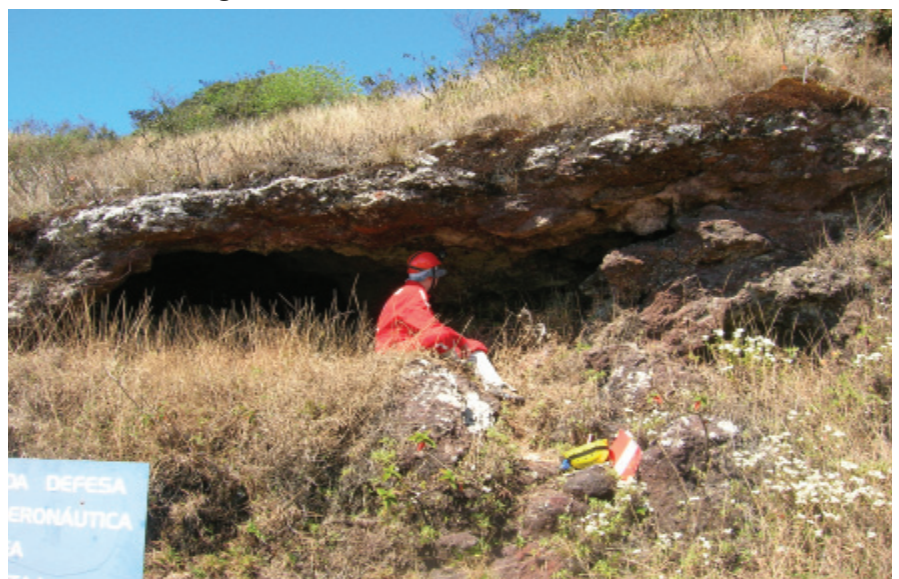

Figura 7 - Caverna da Placa Azul: localizada na ruptura de declive de uma capa de canga detrítica sem continuidade lateral expressiva. Esta capa de canga está localizada no interior da unidade crista.

Foto: Manuela Corrêa Pereira
Quanto ao substrato, foi constatado em campo que as cavidades em tálus são formadas, predominantemente, por blocos de itabirito de tamanho matacão (Figura 8-A). Já as cavernas com feições cársticas e as cavernas sem evidências cársticas possuem como substrato predominante, a canga detrítica (Tabela 2).

No platô superior, foi observado que, no interior destas cavidades, os detritos que compõem a canga são maiores quando comparados aos detritos que compõem a canga das cavernas do platô inferior (Figura 8-B e 8-C). Ainda foi possível constatar que as cavernas do platô superior apresentam porções consideráveis de itabirito. As feições endocársticas das cavernas situadas neste platô são desenvolvidas na litologia supracitadas.

Por fim, a Gruta da Piedade, caverna que apresenta maior projeção horizontal, é diferenciada das demais cavidades por apresentar três litologias: canga detrítica, itabirito in situ e matacões de itabirito (Figura 8-D).

\section{Feições endocársticas e feições exocársticas}

Dentre as cavidades levantadas, cinco cavernas apresentaram feições cársticas que se assemelham às presentes no endocarste das rochas carbonáticas. Dentre estas feições destacam-se preenchimentos, paleopisos, domos, alvéolos e pendentes.

Um preenchimento alterítico ${ }^{1}$ foi encontrado no teto da Gruta do Triângulo. Tal feição pode ser um indício de que esta cavidade estava obstruída por sedimentos, ou seja, sofreu processos de carstificação. Logo o preenchimento encontrado no teto desta gruta, pode ser considerado um produto residual dos sedimentos gerados pelo intemperismo químico concentrado. Isto indica que a cavidade, em algum momento, sofreu a dinâmica paragenética² ${ }^{2}$ (Figura 9-A).

Feições que se assemelham à paleopisos foram constatadas nas cavernas denominadas Gruta da Macumba, Gruta do Chuveirinho e Gruta do Triângulo. Esta feição pode ser uma indicação de duas fases de formação da caverna, comprovando a presença de dois níveis na cavidade. (Figura 9-B).

Feições denominadas domos foram encontradas na Gruta do Cascalhinho. Este tipo de feição pode indicar um período de inundação da cavidade. Desse modo, houve aumento de $\mathrm{CO}_{2}$, possibilitado pelo contato entre a água e o ar. Logo, houve um intenso intercâmbio geoquímico entre o ar carregado deste gás e a rocha. $\mathrm{O}$ resultado desta ação corrosiva pode ser evidenciado nas formas circulares e côncavas encontradas no teto desta Gruta. (Figura 9-C).

\footnotetext{
${ }^{1}$ Resultante da alteração da rocha.

${ }^{2}$ A paragênese é uma dinâmica de escoamento, que condiciona a evolução de uma galeria, agindo no seu próprio entupimento por ação química e acumulação sedimentar (RENAULT, 1968). Desse modo, o preenchimento encontrado na Gruta do Triângulo é uma relíquia, já que os demais sedimentos podem ter sofrido ação química, pois foram dissolvidos ou carreados por esta ação freática. Este último episódio indica uma evoluçao singenética.
} 

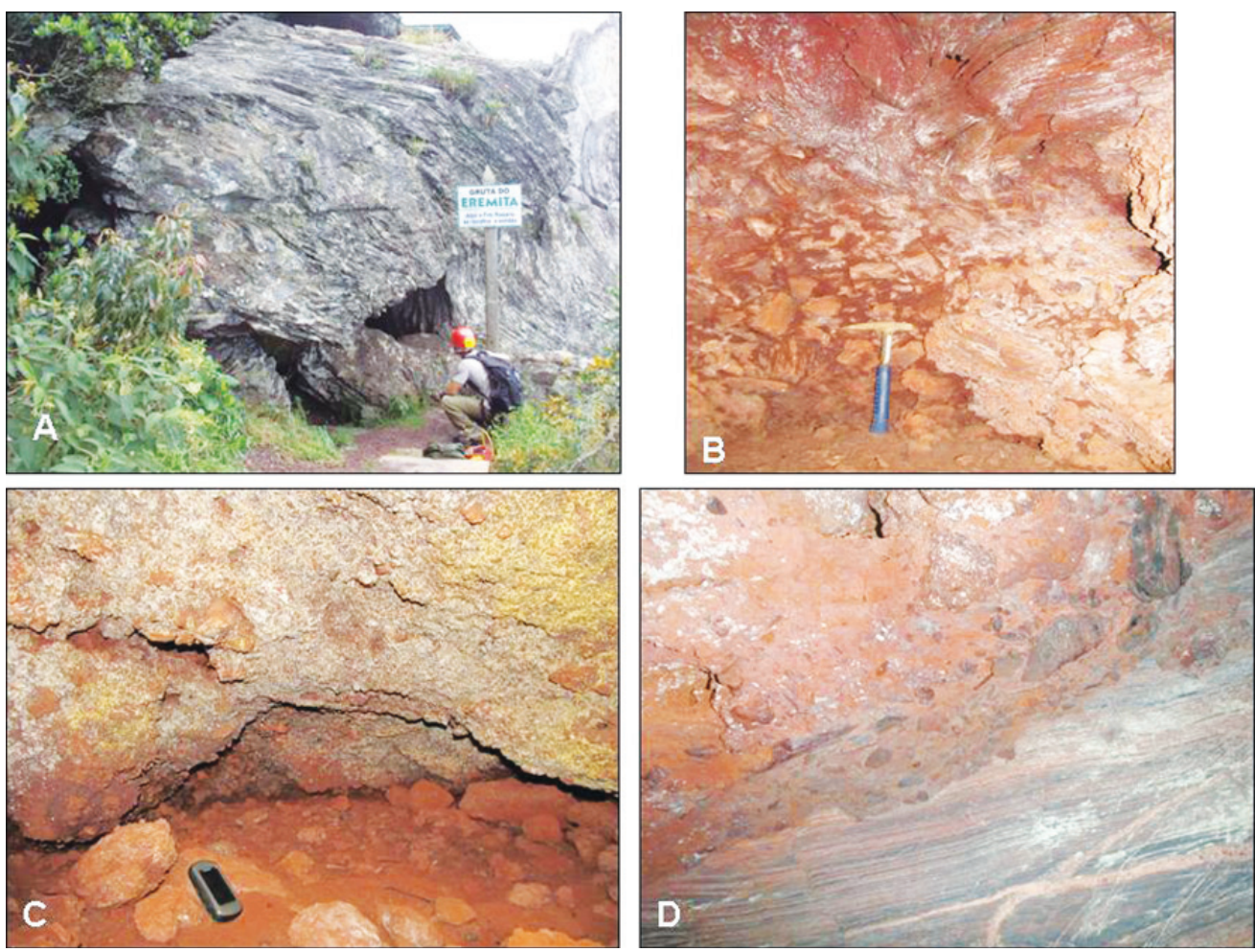

Figura 8 - (A) Gruta do Eremita, formada por matacões de itabirito; (B) Interior da Gruta do Cascalhinho, localizada no platô superior. Na porção superior da foto é possivel constatar a orientação do bloco de itabirito que foi cimentado com os demais detritos da porção inferior da foto. (C) Interior da Gruta do Capim, localizada no platô inferior. Na foto é possivel constatar os detritos, que possuem granulometria de seixos, que compõem a canga detrítica. (D) Gruta da Piedade, localizada na escarpa norte. Na foto constata-se o contato da canga detrítica com o itabirito da Formação Cauê.

Fotos: (A) Roberto Cassimiro; (B), (C) e (D) Manuela Corrêa Pereira.

Feições como álveolos estão presentes tanto na entrada da Gruta da Piedade como no interior da mesma. Alguns autores associam a presença de alvéolos na entrada das cavidades com a ação de agentes orgânicos (Willems et al., 2002). Entretanto, tais feições também são encontradas em seu interior (Figura 9-D). Desse modo, estes alvéolos podem ser vistos como elementos originais que com a coalescência, resultam em tubos (pipes) e anastomoses (Willems et al., 2002; Rodet, 2011).

Pendentes foram constatados na Gruta da Piedade e do Cascalhinho. Esta feição relíquia pode ter indicado a ação dissolutiva da água, que colaborou com a coalescência de dois condutos (Figura 9-E). Piló (2000) considera que esta forma residual é típica do processo paragenético, onde o resultado é a ampliação do conduto pré-existente de forma ascendente.

Dezenas de formas, que se assemelham a Kamenitzas foram encontradas ao longo de blocos e afloramentos de itabirito da Serra da Piedade. Estas feições possuem pequenas dimensões quando comparadas às feições carbonáticas (Figura 9-F). Kamenitza é um termo esloveno que significa bacia. Para Ford \& Williams (2007) esta forma é classificada como "solution pans". Esta forma é caracterizada por uma base plana ou quase plana, onde há a presença de um exutório. No caso das kamenitzas da Serra da Piedade, observa-se que a banda de hematita sobressai-se quando comparada à banda composta por sílica. Logo, pode-se inferir que a solubilidade da banda silicosa é maior do que a banda composta por ferro. Entretanto, esta última também tem sofrido dissolução.

\section{Conclusões}

As cavidades da Serra da Piedade puderam ser classificadas em três categorias: cavidades em tálus, cavernas com feições cársticas e cavernas sem evidências morfocársticas. As cavernas das duas últimas categorias estão localizadas imediatamente abaixo do manto da canga. Entretanto, a cavidade de maior projeção horizontal não apresenta este comportamento.

A inserção na paisagem das cavernas com feições cársticas localizadas nas bordas dos platôs da Serra da Piedade, se difere da localização das cavernas de dissolução descritas por Simmons (1963) e por Piló \& Auler (2005). Já as cavidades formadas por processos exógenos, descritas por Stavale (2007), não foram encontradas na área em estudo. 

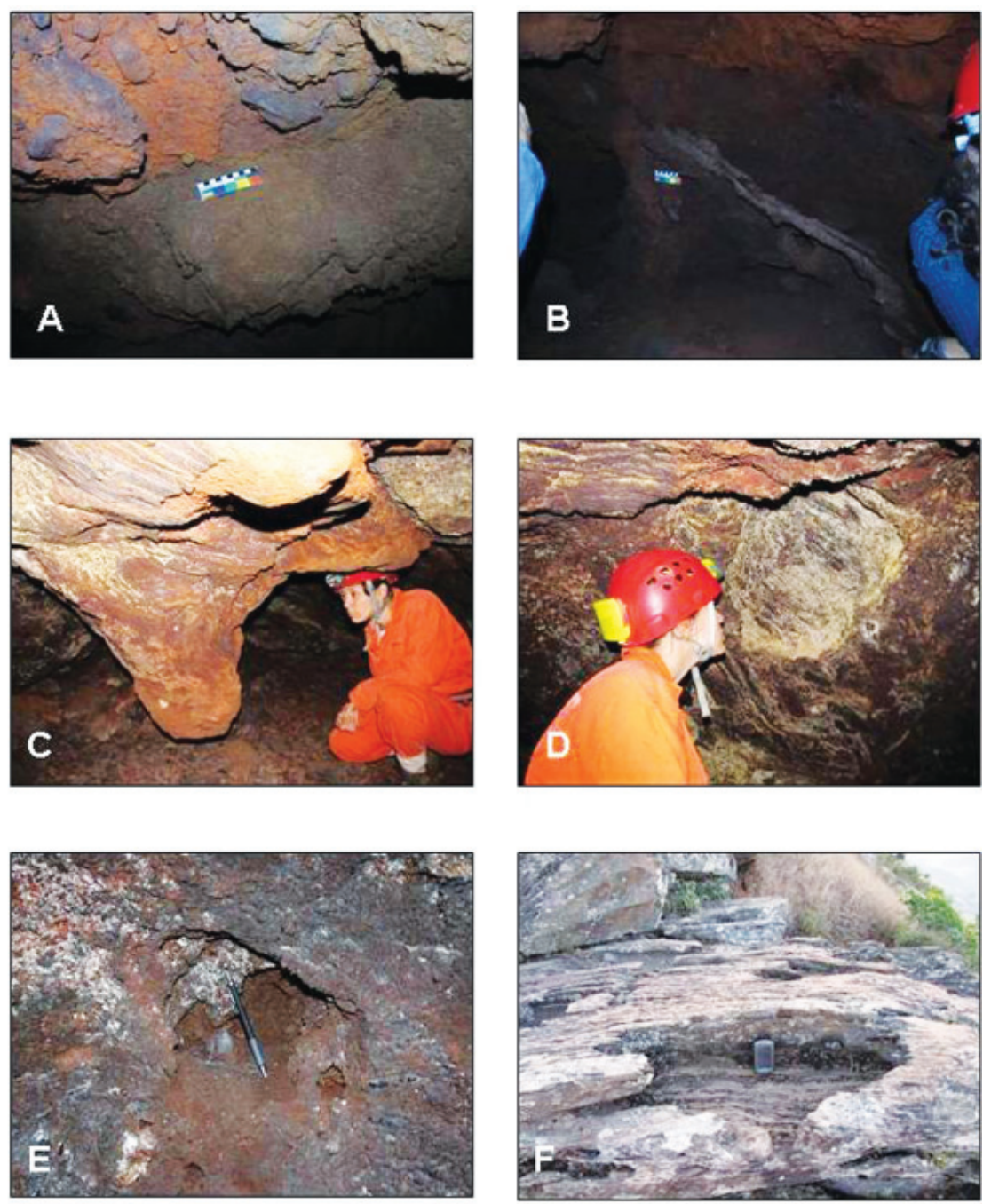

Figura 9 - (A) Preenchimento localizado no teto da Gruta do Triângulo; (B) Resquício de paleopiso presente no interior da Gruta do Triângulo; (C) Pendente presente no interior da Gruta do Cascalhinho; (D) Alveólos constados no interior da Gruta da Piedade; (E) Domo presente no teto da Gruta do Cascalhinho e (F) Kamenitza desenvolvida sobre um bloco de itabirito localizado na unidade crista.

Do ponto de vista da Geomorfologia Cárstica, as formas encontradas nas cavernas com feições cársticas e as feições superficiais de dissolução são interessantes. Elas indicam a ocorrência de processos de carstificação, embora as formas oriundas desses processos não sejam tão desenvolvidas como as feições presentes em rochas carbonáticas e siliciclásticas.

Por fim, em decorrência do grande número de cavidades encontradas na Serra da Piedade - 52 cavidades em 192ha - é possível atestar que as cavernas em itabirito e canga são geoformas recorrentes nestes tipos de substrato. Inclusive, são recorrentes também aquelas que apresentam feições cársticas, pois cinco apresentam estas feições na área de estudo. Sendo assim, e devido a quase ausência de estudos acadêmicos acerca da gênese e evolução destas geoformas, torna-se necessário pesquisas mais aprofundadas sobre este tema. Principalmente para, através de análises geológicas e geoquímicas, explicar a morfogênese e a morfodinâmica destas cavidades.

\section{Agradecimentos}

Aos espeleólogos Luciano Faria e Roberto Cassimiro por todo apoio em campo. Aos membros do Meandros Espeleo Clube e aos alunos da disciplina Geomorfologia Cárstica (do programa de Pós-Graduação em Geografia da UFMG) por todo apoio na etapa de topografia das cavidades e discussões em campo. À graduanda Alice Bessa pelo apoio na compilação dos mapas deste artigo. Por fim, ao CNPQ pela viabilização financeira desta pesquisa. 


\section{Referências bibliográficas}

ALKIMIM, F. F.; MARSHAK, S. Transamazonian orogeny in the Sâo Francisco cráton, Minas Gerais, Brazil: evidence for Paleoproterozoic collision and collapse in the Quadrilátero Ferrífero. Precambrian Research, 90, 29-58. 1998.

BARBOSA, G. V. Quadrilátero Ferrífero. Belo Horizonte: UFMG - Instituto Central de Geociências, 1967.

BARBOSA, G. V. Superfícies de erosão no Quadrilátero Ferrífero, Minas Gerais. Revista Brasileira de Geociências, 10(1):89-101. 1980.

BOWDEN, D. J. Sub-laterite cave systems and other pseudokarst phenomena in thye humid tropics. The example of the kasewe Hills, Sierra Leone. Zeitschrift für Geomorphologie N.F. 24:77-90. 1980.

BOYÉ, M.; PASCUAL, J. F.. Sur la présence d'alunite à la grotte de Fourgassié dans les bauxites des montagnes de Roura (Guyane Française). Revue Géomorphologie Dynamique Paris, 26(1): 1-14. 1977.

DEPARTAMENTO NACIONAL DE PRODUÇÃO MINERAL - DNPM; UNITED STATES DEPARTEMENT OF THE INTERIOR GEOLOGICAL SURVEY. Mapa Geológico da Quadrícula Serra da Piedade, Minas Gerais, Brasil. Whashington: Interior Geological Survey (Escala 1:25.000). 1968.

FORD, D.; WILLIAMS, P. Karst Geomorphology and Hydrology. 1 ed. Boston: Editora Unwin Hyman, 1989.

FORD, D.; WILLIAMS, P. Karst Hydrogeology and Geomorphology. 1 ed. Chichester: Editora Wiley, 2007.

HARDER, E.C.; CHAMBERLIN, R.T. The geology of central Minas Gerais, Brazil. Journal of Geology, 13:341-378, 385424. 1915.

HARDT, R. ; PINTO, S. A. F. Carste em Litologias não Carbonáticas. Revista Brasileira de Geomorfologia, v. 10: 99-105. 2009.

LAMOUNIER, W.L. ; CARVALHO, V. L. M.; SALGADO, A. A. R.; MARENT, B. R. A influência da litologia na distribuição da cobertura vegetal e no uso do solo na Serra do Gandarela, Quadrilátero Ferrífero - $M G$. Revista Geografias, vol. 6(1): 152-165. 2010.

MCFARLANE, M. J.; TWIDALE, C. R. Karstic features associated with tropical weathering profiles. Zeitschrift für Geomorphologie Suppl. Bd, v. 64: 73-95. 1987.

MOSS, R. P. Slope development and soil morphology in a parts of SW Nigéria. Journal of Soil Science, 16:192-209. 1965.

NUNES, B. A.; IBGE. Manual técnico de geomorfologia. Rio de Janeiro: IBGE, 11 p. (Manuais técnicos em geociências; $n^{\circ}$ 5) ISBN 8524005092. 1995.

PALMER, A. N. Cave Geology. 2 ed. Kansas: Allen Press, 454p. 2009.
PILÓ, L. B. Geomorfologia cárstica. Revista Brasileira de Geomorfologia. Minas Gerais, 1(1), p. 88-102. 2000.

PILÓ, L. B.; AULER, A. Cavernas em minério de ferro e canga de Capão Xavier, Quadrilátero Ferrífero, MG. O Carste, 17(3), p. 92-105. 2005.

RENAULT, P. Contribution à l'étude des actions mécaniques et sédimentologiques dans la spéléogenèse - 3e partie: Les facteurs sédimentologiques. Annales de Spéléologie, 23(3): 529-596. 1968.

RODET J. Geomorfologia cárstica - princípios e técnicas. Curso Tópicos Especiais IV, Programa de Pós-Graduação em Geografia, Instituto de Geociências, UFMG, agosto-novembro, Belo Horizonte. 2011.

RIZZINI, C. T. Tratado de fitogeografia do Brasil: aspectos ecológicos. São Paulo: HUCITEC, 1976

RUCHKYS, U. A.; RENGER, F. E.; NOCE, C. M; MACHADO, M. M. M. Serra da Piedade, Minas Gerais: da lenda do Sabarabuçu ao patrimônio histórico, geológico, paisagístico e religioso. Carlos Schobbenhaus; Diógenes de Almeida Campos; Emanuel Teixeira de Queiroz; Manfredo Winge; Mylene Luíza Berbert Born. (Org.). Sítios geológicos e paleontológicos do Brasil. Brasilia: Ministério de Minas e Energia; DNPM; CPRM; SIGEP, v. II. 2007.

SAlGADO, A. A. R.; VARAJÃO, C. A. C.; COLIN, F.; BRAUCHER, R.; NALINI JUNIOR, H. A.; VARAJÃO, A. F. D. O papel da denudação geoquímica no processo de erosão diferencial no Quadrilatero Ferrifero/MG. Revista Brasileira de Geomorfologia. 5(1): 55-69. 2004.

SAlGADO, A. A. R.; VARAJÃO, C. A. C.; VARAJÃO, A. F. D.; NALINI JUNIOR, H. A.; COLIN, F.; BRAUCHER, R. Study of the erosive and denudational processes in the upper Córrego Maracujá Basin (Quadrilátero Ferrífero/MG - Brazil) by the in situ-produced cosmogenic ${ }^{10} \mathrm{Be}$ method. Earth Surface Processes and Landforms, 32: 905-911. 2007a.

SALGADO, A. A. R.; VARAJÃO, C. A. C.; COLIN, F.; BRAUCHER, R.; VARAJÃO, A. F. D.; NALINI JUNIOR, H. A.; CHEREM L. F.; MARENT, B. R.; BRINDUSA, C. B. Estimativa das taxas de erosão das terras altas da alta bacia do Rio das Velhas no Quadrilátero Ferrífero: implicações para a evolução do relevo. Revista Brasileira de Geomorfologia, 8: 1-8. 2007b.

SIMMONS, G. C. Cavernas em canga no Quadrilátero Ferrífero, Minas Gerais, Brasil. O Carste. 17(3): 74-77. 1963.

STÁVALE, Y. O. Cavernas em minério de ferro-Quadrilátero Ferrífero - Parque Estadual do Rola Moça. Monografia Departamento de Geografia da Universidade Federal de Minas Gerais, 2007.

TRICART, J. O Modelado do Quadrilátero Ferrífero Sul de Belo Horizonte. Annales de Geographie, 70 ( $\left.N^{\circ} 379\right)$ : 255272. 1961. 
TWIDALE, C. R. Sinkholes (Dolines) in lateritised sediments, Western Sturt Plateau, Northern Territory, Australia. Geomorphology 1: 33-52. 1987.

VIANELLO, R. L., MAIA, L. F. P. G. Estudo preliminar da climatologia dinâmica do estado de Minas Gerais. Revista Informe Agropecuário, v. 12, n. 138, p. 6-8. 1986.

WILLEMS, L. Phénomènes Karstiques en Roches Silicatées non Carbonatées. Tese - Faculté des Sciences. Université de Liege, Belgique. 2000. 